\title{
Computerized Typesetting and Other New Applications in a Publishing House
}

\author{
Timo Järvi \\ Professor (Emeritus), Computer Science, Department of Information Technology, \\ University of Turku, Finland \\ timojarvi@gmail.com
}

\begin{abstract}
The author was involved during years 1964-67 in a change process from manual typesetting to a computerized one. This paper describes the design and implementation of new graphical applications as well as the programming of IBM 1401. It also presents some reflections on the social affects of these changes.
\end{abstract}

Keywords: Computerized typesetting and hyphenation, Wedgeless line casting, Phone books, Phototypesetting, IBM 1401.

\section{Introduction}

In 1964, I became a summer trainee at the IBM Service Centre in Turku. I had studied mathematics at the University of Turku for three years. The studies included also computer-oriented courses such as algorithms, Turing Machines, structure of a computer, and programming. In addition, I wrote some practical mathematical programs in FORTRAN II and executed them on an IBM 1620 computer. During summer 1964, I programmed some business applications for IBM 1401. This paper describes my experiences, as I was involved full-time in the development of newspaper computer applications between the autumn of 1964 and the winter 1967.

\section{Starting Situation}

In the middle of the 1960s, large companies used computers; applying them to produce newspapers was a rarity. Even if a publishing house had a computer, it used the machine for business applications. In the USA, a handful of newspapers had started computer-typesetting experiments in the first half of the 1960s. Computer typesetting research projects were ongoing in American and European universities, but in Turku, we were not aware of them (see e.g. [1]).

In the spring of 1964, a delegation from Turun Sanomat (the main newspaper in South-West Finland) visited the Graphical Fair in Los Angeles, California, as well as six printing houses experimenting with computer typesetting and other technical novelties. After reporting to CEO Irja Ketonen, they made a decision to develop computer-typesetting applications in Turun Sanomat. The target was not only typesetting 
the daily newspaper, but also phone books and other catalogues published by the company.

Turun Sanomat signed a contract with IBM Finland on 30 June of 1964 to lease an IBM System 360 computer, starting from the beginning of year 1966. Prior to that time, it used an IBM 1401 computer in IBM's local service centre to develop and run typesetting applications $[3,5]$.

\section{First Applications}

In Europe, the first newspaper, that published an article that was hyphenated and line set by a computer, was Turun Sanomat on 9 August 1964. This was only a modest start. In this experiment, a photocopy of a line printer resulted with only capitals used. At that time, the correct hyphenation of the English language was still a big problem. Hyphenation rules of Finnish, however, are very simple except for a few cases. An American linguist, Winthrop Vermillion, working for IBM had written a computer program to hyphenate and line set Finnish printer text. They fed the input using punched cards [3].

Turun Sanomat founded an electronic data processing (EDP) department. Keijo Ketonen, a son of the CEO, was the head of the department and MBA Kaj Arhippainen and I were system planners and programmers. Arhippainen had applications experience using unit record machines in a dairy, but he had not written programs. The first application we wrote, mostly as an EDP exercise for the company, was newspaper advertisement invoicing. It was a typical punch card application for IBM 1401, and we ran monthly. The first month of its deployment was October of 1964.

The second application, the newspaper distribution system, was more complicated. Newspaper deliverers mainly distributed Turun Sanomat in urban areas. In rural areas the newspaper was mailed. The deliverers had a ring of subscriber cards of their district, whereas the addresses of the mail delivery subscribers where written on so called Adrema metal plates and stamped each day on a special paper tape with a piece glued to every newspaper. All subscriptions had an end-of-year renewal. The switch from manual processing of subscriber information to automated processing was a big and uncertain step for the company, and especially for the small EDP department, and required careful planning. We deployed our system for the renewal of all subscriptions in the year shift. All subscriptions required processing in roughly thirty-six hours near the New Year Day.

Data of all subscribers (name and address) appeared in advance on a special mark sense card where details of the subscription could be added with a pencil. The company employed additional seasonal clerks to receive the subscriptions, pick the subscribers' cards, and mark the subscription details. This was because we calculated that we could not key punch the large number of cards (about 100,000) in the short time at the end of the year. An IBM 514 would punch the marked data. During the New Year's Day (newspapers do not appear on the $1^{\text {st }}$ of January) the subscribers' cards were sorted by districts. In urban areas, the subscriber cards for each deliverer's area were printed using a simple program on 1401. The punched cards of the rural subscribers were first divided into four stacks of cards, which were then double collated (using an IBM Card Collator 077) into one stack so that every fourth card originated from the same district. 
This stack was fed into the computer to print out four parallel address tapes so that the card reader and line printer speeds matched. We succeeded to get the last address tapes (foreign subscribers) at 5 a.m. on the $2^{\text {nd }}$ of January.

During the first weeks of the year, we again sorted the cards of the rural subscribers into one stack so that the clerks in the office could add new subscriptions in the proper places. Earlier, Turun Sanomat kept on sending papers to former subscribers even a week or two after the expiration of the subscription, and patiently waited for renewals. Now, a huge number of phone calls came from last year's subscribers who had forgotten to renew their subscription.

After one month, the subscription situation was stable enough to transfer the subscriber file on disks. As there were two disk units with mountable ten surface disk packs, we designed a special triple index sequential (IS) file on both disks. An IS file can be accessed serially very fast as records are mostly in correct order on consecutive tracks. Random access is also possible, because a lookup table for the last records of each track exists. At that time, computer resources were very limited, and we had to exercise great care to be able to run our applications. For example, excessive disk head movement would slow down the printing of address tapes. We divided the rural subscribers into six sub files. Each sub file occupied three tracks on each cylinder and the remaining track served as a common overflow area for the cylinder. We reserved a few last cylinders for a general overflow area in case of the overflow from an overflow track. We needed the overflow areas for updating the files. Note that at that time we did not have terminals for the computer; we made the updates by searching manually the card of the subscriber, by key punching a delete hole on the card, and partly duplicating and punching the new information for the subscriber. We then fed both cards into the updating program that made the changes in the sub files (e.g. changing the address usually required moving the subscriber from one district to another). Using this configuration we could print six (maximum for the printer line width) parallel address tapes with minimum disk read/write head movement, thus leveraging the maximum printer speed. Due to updates the sub files gradually became out of pace so that the arm movement increased and slowed down printing. Thus, we had to reorganize the sub files periodically. This was easy because we could write a sub file read from one unit to the other one in the same way we did originally.

When the manual system was in use, the year shifts included plenty of overtime work in the circulation department. Though the clerks were a little unsatisfied for this, the overtime was a source of extra earnings, welcome during the Christmas time. Transfer to the computerized system with subscriber register on disks reduced the amount of overwork notably; causing some disappointment among the clerks for the loss of extra income.

\section{The IBM 1401}

We now describe briefly the IBM 1401 computer, the platform for our first applications. The smallest addressable unit of memory on the 1400 series was known as the "character" and consisted of eight binary bits (physically, eight ferrite cores). Six of the bits were used for character coding, using a system known as BCD based on the 
code used in IBM punched cards. The seventh bit was used as a parity bit, and the eighth as a "Word Mark". A "Word" on the 1400 series consisted of a variable number of consecutive character positions, the low order address one having the "Word Mark" bit "on". It was, therefore, known as a variable word length machine. Each machine language instruction constituted a "word" and could vary in length between 1,4 , or 7 characters, the first one carrying a word mark. An extra modifying character could be added to each of these formats. Data words were, of course, totally variable in length, and were processed character by character in sequence until the word mark was encountered [2].

We wrote programs using Autocoder, a symbolic assembler language. The variable length instruction started with a one character operation code which also had a word mark. As the opcode for addition was " 1 " this was utilized as a programming trick when increasing a loop counter by giving in the addition instruction the second operand address "*-6" (program counter -6). This referred to the opcode itself, which was now considered as a one character long number 1. Many other tricks made the programs harder to read for others.

In addition to the $1401 \mathrm{CPU}$ the installation concluded a 1402 card reader-punch, a 1403 chain printer, and two 1311 disk storage drives with changeable $2 \mathrm{Mw}$ disk packs. The memory had 12,000 characters, but oddly a customer in the IBM service center was charged according to whether the program used 4,8 , or $12 \mathrm{k}$ of memory.

\section{Typesetting}

Before computer typesetting could be attacked the technical environment had to be modernized. For text input, a special Fairchild paper tape punches were acquired with typesetting keyboards (which had more keys than a type writer). They had no visual output for the key punch operators. The operators quickly learned to read the punched tape codes to solve problematic situations. The mechanical line casting machines were equipped with paper tape readers which at least doubled their speed. A paper tape reader and punch were added to the IBM 1401 computer.

A line setting and hyphenating program acted as a starting point for our typesetting program. The paper tape input to the program was similar to input handled by modern text processing programs; that is, it had paragraphs of text without explicit line breaks with some special formatting codes (caps, italics, bold, font type, size, and end of chapter). For each row of line set text, the program calculated a suitable length and a place for hyphen if needed. It must be noted that newspaper columns are very narrow and Finnish words longer than English ones, so hyphenation is used often. To calculate the length of the present row we had tables of character widths for each font. In hot metal line casting spaces between words were actually special wedges which forced the letter matrices tightly between the borders of a row. These wedges had their minimum and maximum breadth so that a line must fit with minimums and exceed with maximums. If the latter was not achieved, special fixed spaces could be added between words.

We also improved the original hyphenating program by some rare letter combinations and special symbols. The idea was to only use such letter combinations for hyphenation that were always valid, and leave the ambiguous ones out. With this strategy, our program made hyphenation errors only in some compound words and 
foreign names. As a last part, we added special symbols to handle tables (e.g. stock markets and ice hockey or soccer standings) so that the columns would be straight.

Computer typesetting was gradually taken into production use during the spring 1965. Keypunch operators were employed to write reporters' text on punched tape. The tapes were collected and delivered to the nearby IBM service centre by a moped courier. The tapes were input into IBM 1401 which in turn output new tapes to control the line casting machines. These tapes were delivered back to the printing house and fed into line casting machines. One might wonder what the benefits of this complicated process were. First, the keypunch operators were much faster than the line casting machine operators, because they did not have to pay attention to separate lines and hyphenation. Second, the line casting machines could be kept operating at full speed, because they were not dependant on the operators writing speed. Third, the speed of line casting machines further improved because the expensive errors caused by too short or too long rows ceased to exist. Finally, we wanted to gain experience to be able to fully benefit from the company's first computer, expected to be delivered a year later.

\section{The IBM System/360}

IBM announced the System/360 computer in April 1964. As mentioned above, the agreement to acquire this computer was made only two months later. We started to study the new computer, which had an entirely different architecture, in spring 1965 as it was arriving at the beginning of next year. The 1401 only allowed one main program at a time but now also subprograms became available. At that time no courses about programming 360 were given, so we studied the manuals (indeed!). Naturally, there was room for misunderstandings which were later exposed. We wrote a few small test programs and travelled to Paris, France for test runs in the IBM European Test Centre in July 1965. The first thing we noted was that IBM had gone from the BCD to EBCDIC punch card code so that we had to correct quite a lot of special characters before we got the first translations of our assembler programs. After hard five days (computer time was available only by nights) we returned home with the first simple running programs. During the next fall and winter, we ported all our applications for 360 and tested them both in Stockholm, Sweden and Helsinki, Finland.

Meanwhile a computer room was built in the newspaper house. The System/360 had a mainframe with $32 \mathrm{kB}$ main memory, a card reader and punch, line printer, 2 disk units, paper tape reader, and a specially made control unit for 4 paper tape punches, which were located beside the four automatic line casting machines. The new computer system was inaugurated on April 141966.

\section{The Phone Book}

In Finland, new editions of phone books were published yearly. At that time, the type matter of metal rows was stored and the corrections to a new edition were made by line setting the new rows and inserting them manually into the type matter and 
simultaneously removing the obsolete rows. This was both a time consuming and expensive process, and it required plenty of metal and warehouse space.

Our typesetting program could already handle tables, which is what a phone book basically is. Naturally for this application we added special features typical for phone books. We also printed the text with a line printer so that key punching errors could be removed before line casting, which was cheaper. We stored the whole text on disk making the yearly update an easy task. In fact, we started to make the updates regularly and the printouts were used by the telephone company's number service.

The first catalogue produced by this new method was the 1966 edition of SouthWest Finland's phone book. It was a success, and nine years later Turun Sanomat was printing all phone books in Finland.

It was easy to modify the program to handle other kinds of catalogues and Turun Sanomat begun to print many kinds of catalogues in Finland and abroad. This was in accordance of the goals the company set in spring 1964. For this purpose, the first phase of a new printing establishment was completed in spring 1965 [3].

\section{Social Aspects}

Adopting new technology can create resistance. In our case, there were two points that could have raised objections. The feeding of text was moved from expensive line casting machine operators to cheaper and faster key punch operators that belonged to a different labor union. Also the total amount of human work in the typesetting process was reduced and thus could have lead to unemployment.

In Turun Sanomat everything happened smoothly. There was a keen interest in the new technology and many employees took part in the development process. The changes happened slowly and gradually. The new technology gave the company new applications and market opportunities, which were exploited; production grew fast and more people were employed.

\section{Wedgeless Line Casting}

Sometimes the operation of the wedges failed in the line setting and caused a lengthy process to recover. A clever trick was designed to get rid of the wedges. As discussed above, the wedges compressed the letter matrices between the jaws of the machine so that both sides of newspaper columns become straight. There are other alternatives to tighten a row, as nowadays is well known from word processing programs, viz. aligning left (last row of a paragraph) or right, and centering. In these methods the opposing jaw or both move to tighten the row and the wedges remain in their minimum breadth.

The trick was to use centering for all normal lines and replace the wedges, i.e. the word space by exactly counted space or combination of spaces. To get the sides as straight as possible we added two special spaces to the line casting machine, one between the thin and en space and another between the en and em space. Our program counted the word spaces so that they differed from each other at most by the difference of two subsequent spaces from altogether five spaces, and the row had maximum 
length, i.e. no space could be replaced by the next thicker one. By this operation the line casting machine malfunctions decreased and the production speed increased. The maximum difference in line lengths was ca $1 \mathrm{~mm}$, which did not disturb the reader.

\section{Phototypesetting}

The next idea was to get rid of the relatively slow line casting machines. Photomechanical composition had gained users in the USA by the middle of the 1960s. Turun Sanomat decided to adopt this technology, where a typesetting machine had drums of film which had all letters, numbers, and special characters on them. One changeable drum contained eight fonts. By varying the distance between the character on the drum and the film, it was possible to use the same negative image to produce a wide range of type sizes.

The necessary changes to our typesetting programs were small. Now the lines could be filled by given the exact width of space between the words in the line. As also the vertical place of a character was controllable, sub and super script became possible. Naturally, the whole type matter was output as film. This required offset printing, for which a new machinery was acquired later [3].

\section{Design and Implementation of Applications}

The design and development team for all of the applications described above was a group of two men. Several factors helped our small team to succeed. All programs were executed in batch mode, one program at a time. This made the programs simple, because there were no interactions with other programs. In IBM 1401 we used only main programs as the programs were rather short with few repeating parts. The first programs had straightforward logic which was not difficult to program.

The impacts of the new applications to work processes in other departments were manageable. New applications were adopted gradually, one at a time. For a single application, the number of people whose work was affected was moderate.

The idea of adopting new technology for printing came from the top level of company. We thus had full support from the company, and were provided the necessary resources to develop the applications, allowing us to concentrate on the technical problems. Furthermore, there was a sense of pride of the pioneering work, and excitement of the new computer technology. The latter may be much less of a motivating factor in systems development today.

Last but not least, it is important to acknowledge the help received from IBM's local system department. They gave advice in the beginning and took part in various negotiations. The testing trips were essential for our progress as well. To our most difficult questions we often found the answers in IBM's internal manuals that were made available to us.

\section{Conclusion}

The events described in this paper started a revolution in computerizing the graphical industry, according to the U.S. model, not only in Finland but at least in Scandinavia. 
Those involved gave talks and wrote articles and we had interested visitors from Scandinavian countries [4]. In retrospect, the group of people realizing the first steps seems very small, compared to the magnitude of change. What contributed to the success, were knowledge, decisiveness, courage, and resources to make the needed investments. Of course, remarkable progress had taken place in the graphical industry after those early years, and progress continues. The key algorithms and techniques of typesetting, however, were there no later than three years from the initial decision to attempt to computerize typesetting. Those algorithms have since changed relatively little.

\section{References}

[1] Duncan, C.J.: Keynote Address. In: Proceedings of the International Conference on Computerized Typesetting, Washington D.C. (1965), http://www.cs.ncl.ac.uk/ events/anniversaries / 40th/webbook/typesetting/duncan_keynote. html (13.4.2007)

[2] The IBM 1401, http: / /www. columbia.edu/acis/history/1401.html (12.4.2007)

[3] Kalpa, H.: Juoksuflikasta vuorineuvokseksi; Irja Ketonen 1921-1988 (History of the CEO of Turun Sanomat, in Finnish). (Oy Turun Sanomat, Painopalvelut, Serioffset, Turku) (1995)

[4] Ketonen, K.: Turku tietokoneladonnan kärjessä (Turku leads computer typesetting, in Finnish). Graafikko 8/1965, http: / / www. saunalahti.fi/eeromari/graafinen/ ts1.html (14.11.2008)

[5] Vahtera, R.: Matkan määränä kansan menestys (Turun Sanomat 100 years, in Finnish). (TS-yhtymä/Hansaprint Oy, Turku) (2004) 